\title{
John R. Helliwell: Skills for a Scientific Life
}

\author{
Ken Jones ${ }^{1}$
}

(C) Springer-Verlag Berlin Heidelberg 2017

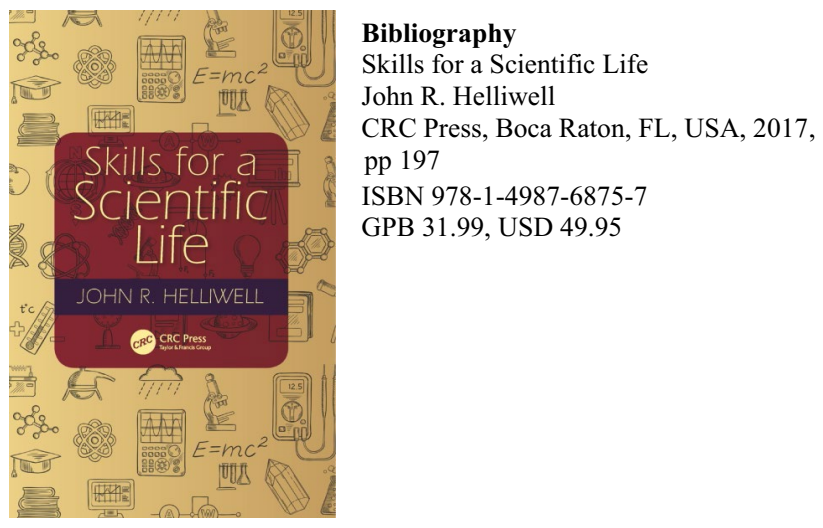

On first sight this book would appear to have appeal to a relatively narrow academic market; how first appearances deceive. Despite the fact that the contents are entirely based upon academic and governmental civil-servant experiences, it (surprisingly) expounds upon a very wide range of management skills that apply to any sector of science. The chapter construction is expertly organised, thus providing a steady flow of connected techniques that eventually turns it into a clearly indexed reference book.

Thirty-four chapters are held within seven sections, an eighth section containing eleven valuable appendices. Consequently most chapters are short, precise and to the point; no superfluous words here! That this author is very well versed in report presentation comes across clearly, an object lesson for the more verbose! Every chapter is headed "How to... A number of these are of universal application: risk assessment (as a management tool); care for your research team; publish and communicate one's results; referee (grant proposals, articles, edit, chair meetings); presentations; lead a team; policy and ethics. All appendices can be universally applied. These are even more concise than the main text, and basically consist of how to conduct oneself. To quote a very apt comment: 'How to keep a budget'; "You are at the mercy of the system your institute weds itself to. The only motto then I think, is to grin and bear it-and start your own spend notebook of course".

OECD statistics indicate more than 30,000 Ph.D. scientists a year graduate from their universities; India around 15,000; China about 30,000. Few will find placements in academia: most will enter industry. Based on these numbers the bar for employment is becoming increasingly higher, representing a massive challenge for those seeking an interesting future in science, especially if $R \& D$ is targeted. It is becoming obvious that only the crème de le crème of scientists can achieve management posts, making the essential skills described here critical if high level posts are to be achieved. The author points out he was privileged to spend 25 years of his career at that most successful postcode for Nobel Prizes, M13 9PL (Manchester University). As a double post-graduate of this illustrious post code (Ph.D., M.B.A.), an iota of this glory must have stuck to me- this review followed the script of "How to write a balanced book review" (Chapter 19) almost to the letter!

This competitively priced must-have book is for anyone with a modicum of ambition towards a scientific career. When put on the retained bookshelf it will be dipped into time and again, offering guidance on how best to progress that career.

Ken Jones

chromatographia@springer.com

1 Knutsford, UK 